\title{
Hospitalists and Intensivists in the Medical ICU: A Prospective Observational Study Comparing Mortality and Length of Stay Between Two Staffing Models
}

\author{
Kristin R. Wise, MD ${ }^{1,5^{*}}$, Valery A. Akopov, MD, FHM ${ }^{1,5}$, Byron R. Williams Jr, MD²,5, Moges S. Ido, MD, MSc, MPH³, \\ Kenneth V. Leeper Jr, MD, FCCP ${ }^{4,5}$, Daniel D. Dressler, MD, MSc, SFHM ${ }^{1,5}$
}

\begin{abstract}
${ }^{1}$ Division of Hospital Medicine, Emory University School of Medicine, Emory University Hospital Midtown (EUHM), Atlanta, Georgia; ${ }^{2}$ Division of

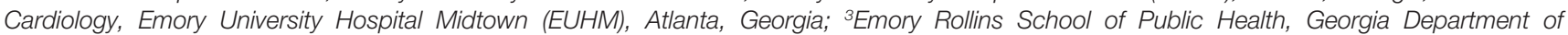
Community Health, Atlanta, Georgia; ${ }^{4} \mathrm{MICU}$ and Respiratory Services, Division of Pulmonary and Critical Care Medicine, Emory University Hospital Midtown (EUHM), Atlanta, Georgia; ${ }^{5}$ Department of Internal Medicine, Emory University School of Medicine, Atlanta, Georgia.
\end{abstract}

BACKGROUND: A shortage of critical care specialists or intensivists, coupled with expanding United States critical care needs, mandates identification of alternate qualified physicians for intensive care unit (ICU) staffing.

OBJECTIVE: To compare mortality and length of stay (LOS) of medical ICU patients cared for by a hospitalist or an intensivist-led team.

DESIGN: Prospective observational study.

SETTING: Urban academic community hospital affiliated with a major regional academic university.

PATIENTS: Consecutive medical patients admitted to a hospitalist ICU team $(n=828)$ with selective intensivist consultation or an intensivist-led ICU teaching team $(n=528)$.

MEASUREMENTS: Endpoints were ICU and in-hospital mortality and LOS, adjusted for patient differences with logistic and linear regression models and propensity scores.

RESULTS: The odds ratio adjusted for disease severity for in-hospital mortality was 0.8 (95\% confidence interval [Cl]:
$0.49,1.18 ; P=0.23)$ and ICU mortality was $0.8(95 \% \mathrm{Cl}$ : $0.51,1.32 ; P=0.41$ ), referent to the hospitalist team. The adjusted LOS was similar between teams (hospital LOS difference 0.9 days, $P=0.98$; ICU LOS difference 0.3 days, $P=0.32$ ). Mechanically ventilated patients with intermediate illness severity had lower hospital LOS (10.6 vs 17.8 days, $P<0.001)$ and ICU LOS (7.2 vs 10.6 days, $P=0.02$ ), and a trend towards decreased inhospital mortality $(15.6 \%$ vs $27.5 \%, P=0.10)$ in the intensivist-led group.

CONCLUSIONS: The adjusted mortality and LOS demonstrated no statistically significant difference between hospitalist and intensivist-led ICU models. Mechanically ventilated patients with intermediate illness severity showed improved LOS and a trend towards improved mortality when cared for by an intensivist-led ICU teaching team. Journal of Hospital Medicine 2012;7:183-189. (c) 2011 Society of Hospital Medicine
Observational studies suggest intensive care unit (ICU) patients have decreased mortality and length of stay (LOS) when cared for by intensivists. ${ }^{1-11}$ This prior literature relies on many small, single-center studies with retrospective designs or historical controls, and compares intensivists to non-intensivists with concurrent inpatient and outpatient responsibilities. ${ }^{1-13}$ These findings are the foundation for patient safety initiatives advocating intensivist involvement with all critically ill patients in urban ICUs. ${ }^{14}$

Critical care workforce evaluations predict a widening disparity between the United States supply and

*Address for correspondence and reprint requests: Kristin R. Wise, MD, Emory School of Medicine, Hospital Medicine Service, Emory University Hospital Midtown (EUHM), 550 Peachtree St NE, Ste 3356, Atlanta, GA 30308; Telephone: 404-433-8608 or 404-686-6730; Fax: 404-686-4837; E-mail: Kristin.Wise@emoryhealthcare.org

Additional Supporting Information may be found in the online version of this article.

Received: March 23, 2011; Revised: July 12, 2011; Accepted: August 15,2011

2011 Society of Hospital Medicine DOI 10.1002/jhm.972

Published online in Wiley Online Library (Wileyonlinelibrary.com). demand for intensivists, ${ }^{15-16}$ raising concern that national ICU staffing with these specialists is not feasible. The most current data suggests that intensivists care for only one-third of ICU patients due to a nationwide shortage. ${ }^{15}$ As a result, other specialists and generalists-including $75 \%$ of hospitalists-provide critical care management. ${ }^{17}$

Despite prevalent hospitalist practice in ICUs, ${ }^{17}$ no studies evaluate their adult ICU patient outcomes, with or without intensivist consultation. Our primary aim was to compare the mortality and LOS of medical ICU patients cared for by a hospitalist team with those of an intensivist-led team. While baseline differences were expected between each teams' patients, we hypothesized that the adjusted patient outcomes would not be different.

\section{METHODS AND PATIENTS Design Overview}

We used a prospective observational design to measure patient mortality and LOS within 2 medical ICU staffing paradigms. This was a collaborative study between the Division of Hospital Medicine and the 
Division of Pulmonary and Critical Care Medicine, with approval from Emory University's Institutional Review Board.

The hospitalist ICU model was staffed by a board certified internal medicine attending, with clinical responsibilities limited to the ICU. An intensivist-led consult team (members distinct from the intensivistled ICU team) was staffed by a board certified pulmonary critical care attending and non-physician providers. This consult team comanaged mechanically ventilated patients and was available for additional critical care consultation at the hospitalists' discretion. The intensivist-led ICU model was staffed by a board certified pulmonary critical care attending, a pulmonary critical care fellow (postgraduate years 4-6) and 4 internal medicine residents (postgraduate years 2-3).

For their respective patients, the hospitalist and intensivist-led teams participated in similar multidisciplinary ICU rounds with the charge nurse, respiratory therapist, and pharmacist. Both teams used the same evidence-based ICU protocols and order sets. The hospitalists and intensivists were aware of the ongoing study.

\section{Setting and Participants}

Our study was conducted in an urban, community teaching hospital that is affiliated with a major regional academic university and has 400 medical-surgical beds, including 56 ICU beds. All medical ICU patients receiving primary medical care from the hospitalist or intensivist-led team were assessed for inclusion between October 2007 and September 2008. Predetermined exclusion criteria included surgery under general anesthesia, outside hospital transfers, pregnancy, and age under 18.

Selection of the admitting ICU team followed existing institutional referral patterns. For emergency department (ED) patients, the ED physicians made the decision to admit to the ICU and contacted an ICU team based on the respiratory support needs of the patient, not the admitting diagnosis. ED patients with respiratory failure who required invasive ventilatory support were admitted to the intensivist-led ICU team. Those without invasive ventilatory support were admitted to the hospitalist ICU team, including ones with respiratory failure requiring noninvasive ventilation. Patients transferred from a hospital floor bed to the ICU by non-hospitalist physicians were assigned to the intensivist-led ICU team, while those transferred by hospitalist floor teams were assigned to the hospitalist ICU team, regardless of diagnosis or respiratory support needs. Patient assignments deviated from these patterns, however, based on ICU teams' census. The intensivist-led ICU team had a strict limit of 20 patients, established by the residency program, and the hospitalist ICU team had a preferred limit of 12 patients.

\section{Measurement of Outcomes and Follow-Up}

Study endpoints were in-hospital and ICU mortality, as well as hospital and ICU LOS. Patient characteristics and outcome data were collected prospectively from medical records and hospital databases by 2 trained research nurses according to study protocol. For data collection training, 1 investigator (K.R.W.) reviewed sample data from 108 patients to ensure consistency and accuracy of data abstraction. Patients with several ICU admissions during 1 hospitalization had ICU data collected only from the first ICU entry, consistent with other trials' methodology., 1,4,10,18-20 Additional ICU entries did not change ICU LOS derived only from the initial entry, but did contribute to hospital LOS. Data from patients with multiple ICU entries was analyzed with the original team assignment. All patients were followed until death or hospital discharge.

\section{Statistical Analysis}

Sample size was determined a priori using an expected inpatient mortality of $10 \%$ from historical data, power of $80 \%$, and 2 -sided alpha of 0.05 to demonstrate no difference in outcomes, defined as a mortality difference of $<5 \%$ between teams. This mortality difference used for the power calculation is consistent with other trial designs. ${ }^{21-25}$ The required sample size was 1306 patients calculated using PASS software (version 2008, NCSS, Kaysville, UT), accounting for an expected 3:2 admission rate to the hospitalists. The statistician was blinded to team assignments.

Clinical characteristics of the groups were compared with the Student $t$ test. The outcome and predictor variable distributions were examined with univariate analyses. Bivariate analyses were calculated for each predictor and endpoint. Multiple logistic and linear regression analyses were performed. Propensity scores were used and defined as the conditional probability of admission to the hospitalist versus intensivist-led ICU team given a patient's covariates. It included all predictors in Table 1 and was calculated using logistic regression. Outcome measures were excluded from the regression.

A generalized linear model (GENMOD), using a binomial distribution and an identity link function, ${ }^{26}$ assessed the in-hospital and ICU mortality rate differences between teams while controlling for major risk factors identified. GENMOD, however, does not accommodate several covariates, as it often fails for lack of convergence. Hence, logistic regression models with adjusted odds ratios (aOR) are reported as well.

The initial logistic regression model for in-hospital and ICU mortality included all 20 independent variables from patient demographics, comorbidities, simplified acute physiology score (SAPS) $\mathrm{II}^{27}$ respiratory support, central venous catheter (CVC) utilization, which included peripherally placed central catheters, and all terms for 2-way interactions with team 
assignment. To determine the best model, a hierarchical backward elimination was executed while assessing for interactions, confounding, and estimate precision. Before removing a regression term, a likelihood ratio test was applied to each coefficient followed by Wald's chi square test. ${ }^{28}$ Collinearity diagnostic for nonlinear models was applied to look for multicollinearity. To exclude variables or regression terms, a condition index of 30 and variance decomposition

\begin{tabular}{|c|c|c|c|}
\hline & $\begin{array}{c}\text { Hospitalist } \\
\text { No. Patients (\%) }\end{array}$ & $\begin{array}{c}\text { Intensivist } \\
\text { No. Patients (\%) }\end{array}$ & $P$ Value \\
\hline Gender-male & $399(48.2)$ & $256(48.5)$ & 0.92 \\
\hline Age-mean (SD) & $61.3(17.9)$ & $60.5(16.3)$ & 0.40 \\
\hline $\operatorname{Race}^{*}$ & & & 0.70 \\
\hline Black & $678(81.9)$ & $426(80.7)$ & \\
\hline White & $141(17.0)$ & $94(17.8)$ & \\
\hline Cardiovascular disease & $660(79.7)$ & $432(81.8)$ & 0.34 \\
\hline Diabetes mellitus & $318(38.4)$ & $212(40.2)$ & 0.52 \\
\hline Renal disease & $288(34.8)$ & $189(35.8)$ & 0.70 \\
\hline Pulmonary disease & $232(28.0)$ & $179(33.9)$ & 0.02 \\
\hline Neurological disorders & $219(26.5)$ & $137(26.0)$ & 0.84 \\
\hline Gl disease & 138 (16.7) & $90(17.1)$ & 0.86 \\
\hline Cancer & $72(8.7)$ & $63(11.9)$ & 0.05 \\
\hline Morbid obesity (BMI $\geq 40$ ) & $72(8.7)$ & $28(5.3)$ & 0.02 \\
\hline HIV/AIDS & $55(6.6)$ & $33(6.3)$ & 0.78 \\
\hline Immunological disorders & $26(3.1)$ & $31(5.9)$ & 0.01 \\
\hline SAPS $\|-$ mean (SD) & $37.4(14.5)$ & $45.1(16.9)$ & $<0.001$ \\
\hline Noninvasive ventilation & $148(17.9)$ & $136(25.8)$ & $<0.001$ \\
\hline Mechanical ventilation & $91(11.0)$ & $274(51.9)$ & $<0.001$ \\
\hline Central venous catheters & $241(29.1)$ & $268(50.8)$ & $<0.001$ \\
\hline
\end{tabular}

Abbreviations: BMI, body mass index; Gl, gastrointestinal; HIV/AIDS, human immunodeficiency virus/ acquired immunodeficiency syndrome; ICU, intensive care unit; SAPS, simplified acute physiology score. *Race was self-identified. proportion of $\geq 0.5$ were used. The final model was evaluated for goodness-of-fit using the Hosmer and Lemeshow test.

LOS was analyzed with linear regression using the same covariates and backward elimination as the logistic model. Goodness-of-fit was evaluated using coefficient of determination $\left(r^{2}\right)$. A variance inflation factor of $\geq 10$ was used to assess for collinearity. Two-sided $P$ values $\leq 0.05$ were considered statistically significant. All analyses were performed with SAS software (version 9.1, SAS Institute, Cary, NC).

\section{RESULTS}

\section{Patients}

A total of 1747 patients received critical care from the hospitalist or intensivist-led teams (Figure 1). Of the 1367 patients who met inclusion criteria, complete data was available for 1356 patients. The ED was the ICU admission source for $68.8 \%$ of hospitalist and $69.9 \%$ of intensivist patients. Baseline patient demographics were similar (Table 1). Among preexisting comorbidities, morbid obesity was more prevalent in hospitalist patients, whereas cancer and pulmonary and immunological diseases were more prevalent in intensivist patients (Table 1).

Hospitalist patients, compared to intensivist patients, had a lower mean SAPS II (37.4 vs 45.1, $P<0.001)$, less noninvasive $(17.9 \%$ vs $25.8 \%, P<0.001)$ and mechanical $(11.0 \%$ vs $51.9 \%, P<0.001)$ ventilation utilization, and fewer CVCs $(29.1 \%$ vs $50.8 \%, P<$ 0.001) (Table 1). The intensivist-led consult team comanaged $18.4 \%$ of the hospitalist patients. These 152 patients had a mean SAPS II of 41 , and $19.7 \%$ required noninvasive ventilation while $44.1 \%$ required mechanical ventilation. For mechanically ventilated hospitalist

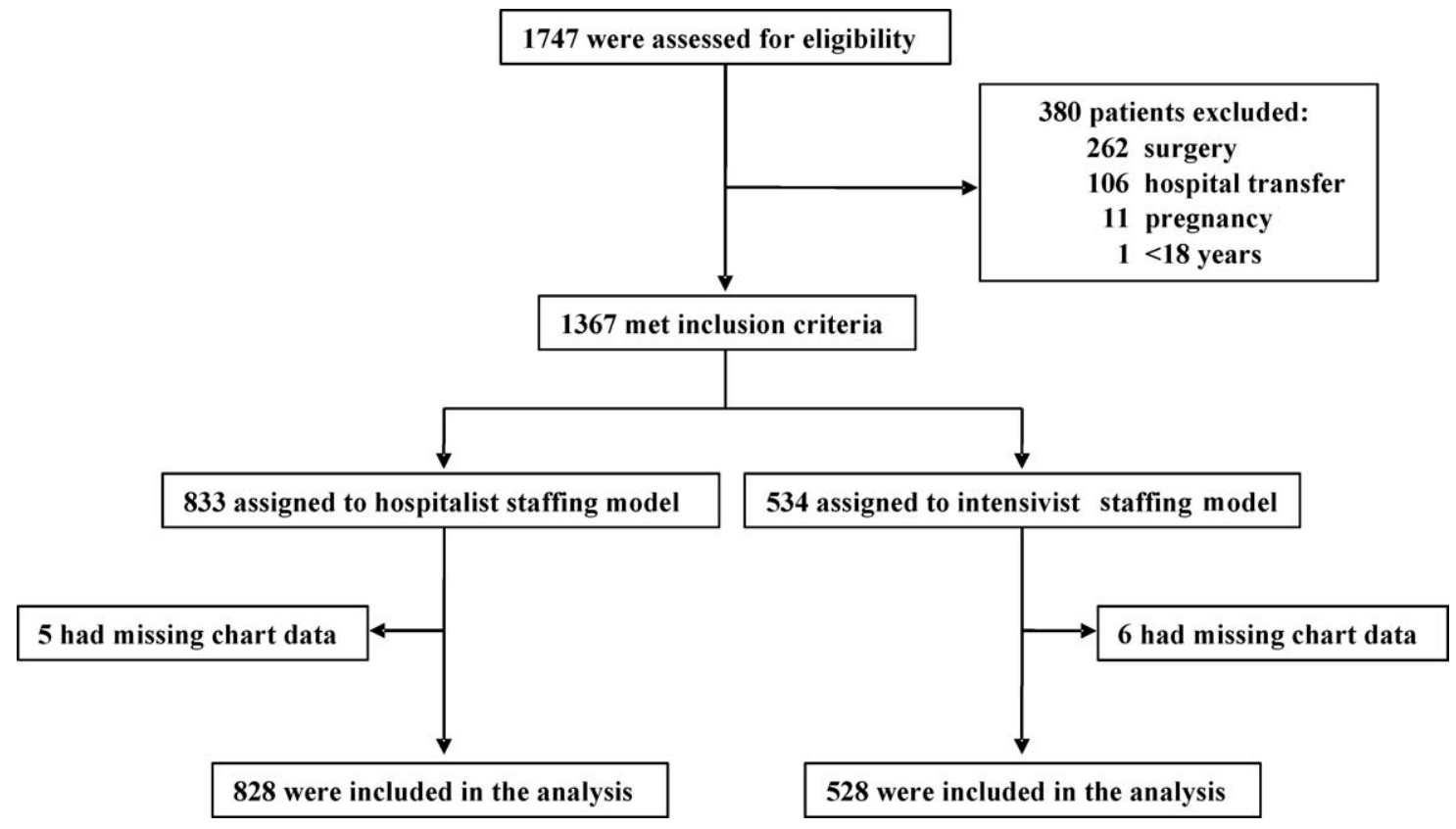

FIG. 1. Screening, enrollment, and follow-up of study participants. 
patients, $80.2 \%$ were comanaged by the intensivist-led consult team, $5.5 \%$ had palliative care for end-of-life management, $6.6 \%$ died imminently, and $7.7 \%$ received short-term ventilation managed by the hospitalist. Hospitalist and intensivist-led teams' ICU readmission rates were similar $(7.0 \%$ vs $5.9 \%, P=0.41)$.

\section{Outcomes}

Of the 1356 patients, there were 168 (12.4\%) deaths and $135(10.0 \%)$ occurred in the ICU. The overall mean ICU LOS was 4.0 days $(\mathrm{SD} \pm 5.9)$, and mean hospital LOS was 9.1 days (SD \pm 9.0$)$. The mean hospital LOS for survivors was 9.0 days (SD \pm 8.8 ).

\begin{tabular}{|c|c|c|c|c|}
\hline & $\begin{array}{l}\text { Hospitalist \% } \\
\text { (No. Died) }\end{array}$ & $\begin{array}{l}\text { Intensivist\% } \\
\text { (No. Died) }\end{array}$ & $\begin{array}{c}\text { Mortality Rate } \\
\text { Difference* } 95 \% \mathrm{Cl}\end{array}$ & $P$ Value \\
\hline \multicolumn{5}{|c|}{ In-hospital mortality } \\
\hline SAPS $\leq 33$ & $1.4(5)$ & $4.4(6)$ & $3.0(0.09,5.80)$ & 0.04 \\
\hline SAPS $34-51$ & $7.9(16)$ & $10.7(24)$ & $2.8(-2.10,7.70)$ & 0.26 \\
\hline SAPS $\geq 52$ & $29.6(40)$ & $40.6(67)$ & $11.0(0.07,21.88)$ & 0.05 \\
\hline \multicolumn{5}{|l|}{ ICU mortality } \\
\hline SAPS $\leq 33$ & $0.6(2)$ & $3.6(5)$ & $3.1(0.80,5.40)$ & 0.01 \\
\hline SAPS $34-51$ & $6.1(20)$ & $9.3(21)$ & $3.3(-1.17,7.70)$ & 0.15 \\
\hline \multirow[t]{2}{*}{ SAPS $\geq 52$} & $22.2(30)$ & $34.6(57)$ & $12.3(2.02,22.63)$ & 0.02 \\
\hline & $\begin{array}{l}\text { Hospitalist Days } \\
\text { (No. Patients) }\end{array}$ & $\begin{array}{l}\text { Intensivist Days } \\
\text { (No. Patients) }\end{array}$ & $\begin{array}{c}\text { LOS } \\
\text { Difference }^{\dagger} 95 \% \mathrm{Cl}\end{array}$ & $P$ Value \\
\hline \multicolumn{5}{|l|}{ Hospital LOS } \\
\hline SAPS $\leq 33$ & $6.0(363)$ & $8.2(138)$ & $2.2(0.81,3.60)$ & 0.002 \\
\hline SAPS $34-51$ & $9.8(330)$ & $9.2(225)$ & $-0.6(-2.01,0.77)$ & 0.38 \\
\hline SAPS $\geq 52$ & $10.9(135)$ & $13.4(165)$ & $2.5(-0.15,5.15)$ & 0.06 \\
\hline \multicolumn{5}{|l|}{ ICULOS } \\
\hline SAPS $\leq 33$ & $2.2(363)$ & $3.8(138)$ & $1.6(0.89,2.27)$ & $<0.001$ \\
\hline SAPS 34-51 & $3.5(330)$ & $4.9(225)$ & $1.4(0.44,2.31)$ & 0.004 \\
\hline$S A P S \geq 52$ & $4.7(135)$ & $7.4(165)$ & $2.7(0.84,5.60)$ & 0.005 \\
\hline
\end{tabular}

\section{Bivariate Outcomes}

Patients were stratified for bivariate analysis into 3 tiers based on SAPS II to reflect low $(\leq 33)$, intermediate (34-51), and high ( $\geq 52)$ disease acuity corresponding to a predicted mortality of $<15 \%$, between 15 and $50 \%$, and $>50 \%$ (Table 2). Those with intermediate severity only showed an ICU LOS difference that was shorter for hospitalist patients. All remaining strata demonstrated lower mortality and LOS among the hospitalist patients (Table 2).

\section{Adjusted Outcomes}

The logistic and linear regression models include covariates detailed in the Table 3 legend and are referent to the hospitalist team. Logistic regression models demonstrated no difference in adjusted in-hospital mortality (aOR 0.8 [95\% confidence interval (CI): $0.49,1.18], P=0.23$ ) and adjusted ICU mortality (aOR 0.8 [95\% CI: 0.51, 1.32], $P=0.41$ ) between the 2 ICU staffing models (Table 3 ). Linear regression models also demonstrated no difference in adjusted hospital LOS difference $(-0.9$ days [95\% CI: -1.88 , $0.12], P=0.98)$ and adjusted ICU LOS $(-0.3$ days [95\% CI: $-0.92,0.30], P=0.32$ ) (Table 3). Outcomes were re-analyzed using propensity scores within the regression models, yielding similar results that did not change the estimate or improve precision. The overall results also remained comparable when calculations were repeated, excluding patient outliers (SAPS II $>75$ or hospital LOS $>30$ days).

\section{Subgroup Analysis}

Since each team's respiratory support utilization differed greatly and was a significant variable in the logistic and linear regression models, we performed subgroup analysis of mechanically ventilated patients (Table 4). Without mechanical ventilation, no significant outcome differences were detected between the

\begin{tabular}{|c|c|c|c|c|c|c|}
\hline & Adjusted Mortality Difference [\%] $(95 \% \mathrm{Cl})$ & $P$ Value & Adjusted Mortality OR (95\% Cl) & $P$ Value & Mean LOS ${ }^{\S}$ Difference [days] $(95 \% \mathrm{Cl})$ & $P$ Value \\
\hline \multicolumn{7}{|c|}{ All patients $(n=1356)$} \\
\hline In-hospital & $-0.3(-1.83,1.19)$ & 0.68 & $0.8(0.49,1.18)$ & 0.22 & $-0.9(-1.88,0.12)$ & 0.98 \\
\hline ICU & $0.2(-1.19,1.57)$ & 0.79 & $0.8(0.51,1.32)$ & 0.41 & $-0.3(-0.92,0.30)$ & 0.32 \\
\hline \multicolumn{7}{|c|}{ Without MV ${ }^{\dagger}(n=991)$} \\
\hline In-hospital & $-0.2(-1.97,1.57)$ & 0.82 & $0.8(0.38,1.56)$ & 0.47 & $-0.2(-1.12,0.78)$ & 0.72 \\
\hline ICU & $0.4(-1.29,2.12)$ & 0.63 & $1.0(0.44,2.27)$ & 0.99 & $-0.03(-0.39,0.34)$ & 0.89 \\
\hline \multicolumn{7}{|c|}{ With $\mathrm{MV}^{\ddagger}(\mathrm{n}=365)$} \\
\hline In-hospital & $-2.7(-13.69,8.22)$ & 0.62 & $0.8(0.45,1.45)$ & 0.48 & $-2.0(-4.74,0.66)$ & 0.14 \\
\hline ICU & $-5.2(-16.10,5.69)$ & 0.35 & $0.7(0.38,1.25)$ & 0.26 & $-0.2(-2.18,1.74)$ & 0.82 \\
\hline
\end{tabular}

NOTE: Mortality rate differences and OR are referent to the hospitalist. Mean LOS difference equals intensivist-led team mean LOS minus hospitalist mean LOS. Abbreviations: Cl, confidence interval; CVC, central venous catheters; Gl, gastrointestinal; ICU, intensive care unit; LOS, length of stay; MV, mechanical ventilation; OR, odds ratios; SAPS, simplified acute physiology score. * In-hospital mortality model adjusted for the variables: SAPS II, MV, CVC, and preexisting cancer. ICU mortality model adjusted for the variables: SAPS II, noninvasive ventilation, MV, CVC, gender; preexisting cancer, cardiovascular and pulmonary diseases. ${ }^{\dagger}$ In-hospital mortality model adjusted for the variables: SAPS II, noninvasive ventilation, CVC, and preexisting cancer. ICU mortality model adjusted for the variables: SAPS II, noninvasive ventilation, CVC, and preexisting cardiovascular disease. ${ }^{\ddagger}$ In-hospital mortality model adjusted for the variables: SAPS II, CVC, gender; preexisting diabetes, immunological disorders, and pulmonary disease. ICU mortality model adjusted for the variables: SAPS II, CVC, gender; preexisting cancer, diabetes, immunological disorders, and pulmonary disease. ${ }^{~ H o s p i t a l ~ L O S ~ m o d e l ~ a d j u s t e d ~ f o r ~ t h e ~ v a r i a b l e s: ~ S A P S ~ I I, ~ n o n i n v a s i v e ~ v e n t i l a t i o n, ~ M V, ~ C V C, ~ a n d ~ p r e e x i s t i n g ~ d i a b e t e s ~ m e l l i t u s, ~ G l ~ a n d ~ p u l m o n a r y ~ d i s e a s e s . ~ I C U ~ L O S ~ m o d e l ~}$ adjusted for the variables: SAPS II, noninvasive ventilation, MV, CVC; preexisting obesity, Gl and chronic kidney diseases. ${ }^{*}+\Varangle$ SAll regression model variables based on a backward stepwise elimination of covariates. 
TABLE 4. Subgroup Analysis: Stratified Mortality and Length of Stay of Patients With and Without Mechanical Ventilation

\begin{tabular}{|c|c|c|c|c|c|c|}
\hline & \multicolumn{3}{|c|}{ Without Mechanical Ventilation } & \multicolumn{3}{|c|}{ With Mechanical Ventilation } \\
\hline SAPS $\leq 33$ & $1.4(5)$ & $2.2(2)$ & 0.63 & $0.0(0)$ & $8.9(4)$ & 0.22 \\
\hline SAPS $34-51$ & $5.2(15)$ & $4.3(5)$ & 0.72 & $27.5(11)$ & $17.4(19)$ & 0.18 \\
\hline SAPS $\geq 52$ & $20.0(20)$ & $15.6(7)$ & 0.53 & $57.1(20)$ & $50.0(60)$ & 0.46 \\
\hline SAPS $34-51$ & $3.1(9)$ & $3.5(4)$ & 0.86 & $27.5(11)$ & $15.6(17)$ & 0.10 \\
\hline \multirow[t]{3}{*}{ SAPS $\geq 52$} & $11.0(11)$ & $11.1(5)$ & 0.98 & $54.3(19)$ & $43.3(52)$ & 0.26 \\
\hline & Hospitalist & Intensivist & $P$ & Hospitalist & Intensivist & $P$ \\
\hline & Days (Patients) & Days (Patients) & Value & Days (Patients) & Days (Patients) & Value \\
\hline \multicolumn{7}{|l|}{ Hospital LOS } \\
\hline SAPS $\leq 33$ & $1.9(347)$ & $2.2(93)$ & 0.30 & $8.0(16)$ & $7.0(45)$ & 0.67 \\
\hline SAPS 34-51 & $2.6(290)$ & $2.8(116)$ & 0.52 & $10.6(40)$ & $7.2(109)$ & 0.02 \\
\hline SAPS $\geq 52$ & $3.5(100)$ & $2.8(45)$ & 0.17 & $8.1(35)$ & $9.2(120)$ & 0.61 \\
\hline
\end{tabular}

NOTE: All patients included in analyses (hospitalist ICU team patients: $n=828$ with 91 requiring mechanical ventilation; intensivist-led ICU team patients: $n=528$ with 274 requiring mechanical ventilation). Abbreviations: LOS, length of stay; SAPS, simplified acute physiology score.

intensivist and hospitalist groups when stratified by disease severity (Table 4).

With mechanical ventilation, patients with intermediate illness severity had a significantly shorter hospital LOS (10.6 vs 17.8 days, $P<0.001)$ and ICU LOS (7.2 vs 10.6 days, $P=0.02$ ) when managed by the intensivist-led team (Table 4). When the calculations were repeated for only the patients who survived hospitalization, the shorter ICU LOS (6.5 vs 10.9 days, $P$ $=0.01)$ remained significant but not the hospital LOS (10.3 vs 19.3 days, $P=0.10$ ). The patients with intermediate acuity also showed a trend toward a decreased ICU mortality $(15.6 \%$ vs $27.5 \%, P=0.10)$ when managed by the intensivist-led team (Table 4).

Adjusting for relevant risk factors, no statistically significant mortality rate difference was demonstrated between the hospitalist and intensivist-led teams when evaluating all patients or patients without mechanical ventilation. The result, however, was inconclusive for patients with mechanical ventilation and did not allow refutation of the null hypothesis because the confidence interval for the mortality rate difference crossed the prespecified mortality difference threshold for clinical significance (Figure 2).

\section{DISCUSSION}

We present the first prospective evaluation of adult patient outcomes comparing intensivist-led and hospitalist ICU staffing models. This study was powered to demonstrate no difference in hospital and ICU mortality between these ICU staffing models at a single

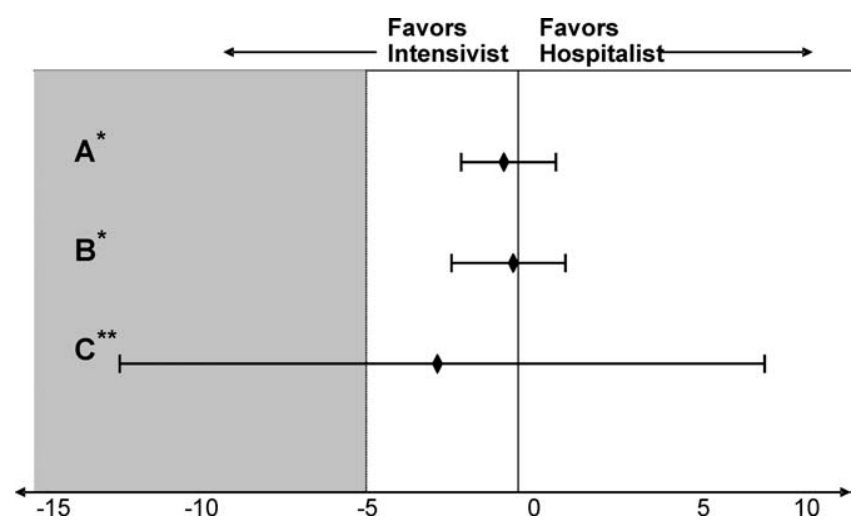

FIG. 2. Adjusted in-hospital mortality difference (\%) and confidence intervals $(\mathrm{Cl})$ between the hospitalist intensive care unit (ICU) team and intensivist-led ICU team. (A) All patients: adjusted for simplified acute physiology score (SAPS) II, mechanical ventilation (MV), central venous catheters (CVC); (B) patients without MV: adjusted for SAPS II, CVC; (C) patients with MV: adjusted for SAPS II, CVC. Bars indicate 2-sided 95\% $\mathrm{Cl}$. *Results indicate the adjusted in-hospital mortality difference between hospitalist team and intensivist-led team is no different if $\mathrm{Cl}$ crosses the null value (zero). ${ }^{\star \star}$ Result indicates the adjusted in-hospital mortality difference between hospitalist team and intensivist-led team is inconclusive if $\mathrm{Cl}$ crosses both the null value and the shaded area.

university-affiliated community hospital, though subgroups were not accounted for in these calculations. Consistent with our observational design, we did not influence or change established triage systems. This led to expected significant differences in baseline patient severity of illness and mechanical ventilation use. We adjusted for these and other potential confounders by stratifying patients with SAPS II, examining mechanically ventilated patients separately, and 
using logistic and linear regression models and propensity scores, recognizing that unmeasured differences in illness severity may remain. ${ }^{29}$

Our initial adjustment for baseline patient disparities between teams used bivariate analysis with SAPS II to stratify patients into 3 tiers to reflect low $(\leq 33)$, intermediate (34-51), and high $(\geq 52)$ disease acuity. Hospitalist patients with intermediate acuity comprised the only tier without decreased in-hospital and ICU mortality when compared to the intensivist intermediate patients (Table 2). We suspect these mortality differences are related to the intensivist patients' increased mechanical ventilation utilization seen at all acuity levels. Hospitalist patients had a significantly shorter hospital LOS for low-acuity patients and significantly shorter ICU LOS for all severity groups (Table 2). This lower LOS may stem from greater efficiency of hospitalist ICU attendings managing transitions from the ICU in conjunction with other hospitalist colleagues. It also may reflect other unmeasured factors that affected illness severity in the intensivist patients.

When patients were stratified by both SAPS II and mechanical ventilation status, the lower mortality and LOS findings previously seen with hospitalist patients were no longer apparent (Table 4). Interestingly, patients with intermediate or high SAPS II requiring mechanical ventilation had lower mortality $(\geq 10 \%$ absolute difference) in the intensivist-led team-albeit none reached statistical significance, probably due to small subgroup sizes (Table 4). Intensivist patients requiring mechanical ventilation also had a statistically significant shorter hospital LOS in the intermediate acuity patients (Table 4). These results contradict the controversial findings by Levy et al. which suggested that ICU patients with intermediate disease acuity have increased hospital mortality when cared for by intensivists versus non-intensivists. ${ }^{18}$ We postulate these demonstrated differences likely reflect intensivist training and experience in caring for mechanically ventilated, higher acuity patients. Surprisingly, the presence of an intensivist-led consult team did not mitigate the mortality and LOS differences seen for mechanically ventilated patients on the hospitalist team. Perhaps intensivist expertise was underutilized when they served in the consultant role.

The adjusted outcomes using multivariable analysis with logistic and linear regression models did not find a statistically significant difference in mortality or LOS, regardless of mechanical ventilation status (Table 3). These statistical models used 20 patient variables and identified key variables with the greatest impact-SAPS II, mechanical ventilation, and CVC presence. We next examined mortality differences adjusting only for these 3 variables and were unable to detect a statistically significant mortality difference between the teams (Figure 2). We suspect that a CVC is not an independent risk factor but instead a surro- gate marker of illness severity and likely of vasopressor use.

\section{Study Limitations}

Our study has several obvious limitations. It uses an observational design within a single hospital. However, this is seen in prior comparisons of intensivists to non-intensivists. ${ }^{1-5,8-10}$ Our study is unique with its prospective design and sample-size calculation to demonstrate no difference in outcomes. Because our data is from a single center, it eliminates practice differences encountered when comparing multiple institutions, but it may also limit its generalizability.

Another major limitation in our comparison of an intensivist-led ICU team to a hospitalist ICU team is their composition. Instead of 2 multidisciplinary teams, we compared a hospitalist's performance to that of a group of physicians at various levels of training. Similar comparisons have been seen in prior studies. For example, in the large study by Levy et al., half of the intensivists studied were in academic centers affiliated with teaching teams. ${ }^{18}$ Housestaff involvement, however, may have confounded the intensivist-led team's patient outcomes. Tenner et al. demonstrated improved survival and decreased LOS in a pediatric ICU when hospitalists provided after-hours coverage instead of residents. ${ }^{30}$ Furthermore, the patient census varied between the ICU teams, potentially impacting outcomes. While each service had only 1 attending, the hospitalist team had 1 clinician caring for patients whereas the intensivist-led team had 5 to 6 clinicians. This study's implications may be more relevant to academic centers. A similar study of hospitalists and intensivists conducted in a nonteaching institution may yield different results.

Our 2 patient groups had substantial differences in illness severity and mechanical ventilation. Despite statistical techniques to address potential confounders in observational trials including stratification, multivariable adjustment, and propensity scores, ${ }^{29}$ residual confounders may still remain that influence the results and thus our conclusions. SAPS II is a validated method to objectively quantify disease severity and provide predictive mortality, ${ }^{27}$ however, it has known deficiencies. The use of propensity scores may not fully account for selection biases in team assignments introduced by the ED physicians. Biases may stem from the ICU teams' awareness of the ongoing study, and each team may have tried to maintain improved outcomes.

Additionally, the mortality outcomes represent in-hospital mortality, not 30-day mortality. This may be a lessuseful indicator of ICU performance because of postICU transitions to extended care facilities and emphasis on end-of-life care. The majority of patients from both ICU models, however, did transfer to inpatient medical units under the care of non-ICU hospitalist teams. Furthermore, this study did not capture important outcomes reported in other investigations, such as discharge disposition or quality of life after discharge. ${ }^{31-32}$ Finally, 
the adjusted odds ratio for the intensivist-led team's inhospital mortality (aOR $0.8, P=0.23$ ), referent to the hospitalist, does not eliminate the possibility that an intensivist-led model may reduce mortality risk.

Our study suggests that intermediate- and high-acuity, mechanically ventilated patients may benefit from care by intensivists rather than hospitalists. The results from this initial study could be used to design and estimate sample size for future studies of hospitalists and intensivists to elucidate risk reduction. Randomized and multicenter trials are needed to provide more robust data, because our subgroups were small and not accounted for in the sample size calculation. Considering the severe intensivist shortage, 1 strategy to provide effective and efficient coverage of the growing American ICU population may be to ask hospitalists to care independently for lower acuity ICU patientsespecially nonventilated patients-while encouraging or requiring intensivist care for higher acuity patients, especially once mechanically ventilated.

\section{Conclusion}

We anticipate this initial study of hospitalist and intensivist-led ICU teams will validate a hospitalist ICU staffing model for further investigation. We propose that hospitalists can provide quality care for lower acuity critical care patients. This may improve intensivist availability to higher acuity critically ill patients and allow for judicious utilization of the limited intensivist supply. Future studies may better delineate specific subgroups of critically ill patients who benefit most from intensivist primary involvement. Additional research may also help generate evidence-based triage standards to appropriate critical care teams and foster guideline development. Hospitalists may be instrumental in the critical care staffing shortage, however, identification of their ideal role requires further study.

\section{Acknowledgements}

The authors thank Ralph Bailey, RN; Daniel S. Budnitz, MD, MPH; Kirk Easley, MPH; Michael Heisler, MD, MPH; Joan Lopez, RN; Jason Stein, MD; and David Tong MD, MPH for their support and contributions.

Disclosure: This study was supported by grants from the Carlyle Fraser Heart Center and the Department of Medicine at Emory University. The funders had no role in the study design, data collection, data analysis and interpretation, or manuscript writing. No potential conflict of interest relevant to this article was reported.

\section{References}

1. Li TC, Phillips MC, Shaw L, Cook EF, Natanson C, Goldman L. Onsite physician staffing in a community hospital intensivist care unit. JAMA. 1984;252(15):2023-2027.

2. Reynolds HN, Haupt MT, Thill-Baharozian MD, Carlson RW. Impact of critical care physician staffing on patients with septic shock in a university hospital medical intensive care unit. JAMA. 1988; 260(23):3446-3450.

3. Brown JJ, Sullivan G. Effect on ICU mortality of a full-time critical care specialist. Chest. 1989;96(1):127-129.

4. Carson SS, Stockings C, Podsadecki T, et al. Effects of organizational change in the medical intensive care unit of a teaching hospital. JAMA. 1996;276(4):322-328.

5. Manthous CA, Amoateng-Adjepong Y, al-Kharrat T, et al. Effects of a medical intensivist on patient care in a community teaching hospital. Mayo Clin Proc. 1997;72(5):391-399.
6. Multz AS, Chalfin DB, Samson IM, et al. A 'closed' medical intensive care unit (MICU) improves resource utilization when compared with an 'open' MICU. Am J Respir Crit Care Med. 1998;157(5): 1468-1473.

7. Pronovost PJ, Jencks M, Dorman T, et al. Organizational characteristics of intensive care units related to outcomes of abdominal aortic surgery. JAMA. 1999;281(14):1310-1312.

8. Hanson CW III, Deutschman CS, Anderson HL III, et al. Effects of an organized critical care service on outcomes and resource utilization: a cohort study. Crit Care Med. 1999;27(2):270-274.

9. Blunt MC, Burchett KR. Out-of-hours consultant cover and case-mix adjusted mortality in intensive care. Lancet. 2000;356:735-736.

10. Baldock G, Foley P, Brett $S$. The impact of organizational changes on outcomes in an intensive care unit in the United Kingdom. Intensive Care Med. 2001;27:865-872.

11. Fuchs RJ, Berenholtz SM, Dorman T. Do intensivists in ICU improve outcome? Best Pract Res Clin Anaesthesiol. 2005;19(1):125-135.

12. Pronovost PJ, Angus DC, Dormal T, et al. Physician staffing patterns and clinical outcomes in critically ill patients: a systemic review. JAMA. 2002;288(17):2151-2162.

13. Young MP, Birkmeyer JD. Potential reduction in mortality rates using an intensivist model to manage intensive care units. Eff Clin Pract. 2000;3(6):284-289.

14. The Leapfrog Group Fact Sheet. ICU Physician Staffing Fact Sheet. Available at: http://www.leapfroggroup.org/media/file/Leapfrog _ICU_Physician_Staffing_Fact_Sheet.pdf and http://www.leapfrog group.org/media/file/Fact_Sheet_Leapfrog_Group.pdf. Accessed November 8, 2009.

15. Angus DC, Kelley MA, Schmitz RJ, White A, Popovich J Jr. Committee on Manpower for Pulmonary and Critical Care Societies (COMPACCS). Current and projected workforce requirements for care of the critically ill and patients with pulmonary disease: can we meet the requirements of an aging population? JAMA. 2000;284(21): $2762-2770$.

16. US Department of Health and Human Services, Health Resources and Services Administration (HRSA). Report to Congress: the critical care workforce; a study of the supply and demand for critical care physicians. Senate Report 108-181. Rockville, MD: HRSA; May 2006.

17. Miller J, Kealey B. 2007-2008 Survey: The Authoritative Source on the State of the Hospital Medicine Movement. Philadelphia, PA: Society of Hospital Medicine; 2008.

18. Levy MM, Rapoport J, Lemeshow S, Chalfin DB, Phillips G, Danis $M$. Association between critical care physician management and patient mortality in the intensive care unit. Ann Intern Med. 2008; 148(11):801-809.

19. Knaus WA, Wagner DP, Zimmerman JE, Draper EA. Variations in mortality and length of stay in intensive care units. Ann Intern Med. 1993;118(10):753-761.

20. Tarnow-Mordi WO, Hau C, Warden A, Shearer AJ. Hospital mortality in relation to staff workload: a 4-year study in an adult intensivecare unit. Lancet. 2000;356:185-189.

21. Finfer S, Bellomo R, Boyce N, et al. A comparison of albumin and saline for fluid resuscitation in the intensive care unit. N Engl J Med. 2004;350(22):2247-2256.

22. Hebert PC, Wells G, Blajchman MA, et al. A multicenter, randomized controlled clinical trial of transfusion requirements in critical care. $N$ Engl J Med. 1999;340(6):409-417.

23. Rivers E, Nguyen B, Havstad S, et al. Early goal-directed therapy in the treatment of severe sepsis and septic shock. N Engl J Med. 2001; 345(19):1368-1377.

24. Van den Berghe G, Wouters P, Weekers F, et al. Intensive insulin therapy in critically ill patients. N Engl J Med. 2001;345(19):1359-1367.

25. Wheeler AP, Bernard GR, Thompson BT, et al. Pulmonary-artery versus central venous catheter to guide treatment of acute lung injury. $N$ Engl J Med. 2006;354(21):2213-2224.

26. Spiegelman D, Herzmark E. Easy SAS calculations for risk or prevalence ratios and differences. Am J Epidemiol. 2005;162(3):199-200.

27. LeGall JR, Lemeshow S, Saulnier F. A new simplified acute physiology score (SAPS II) based on a European/North American multicenter study. JAMA. 1993;270(24):2957-2963.

28. Kleinbaum DG. Epidemiologic methods: the "art" in the state of the art. J Clin Epidemiol. 2002;55(12):1196-1200.

29. Wunsch H, Linde-Zwirble WT, Angus DC. Methods to adjust for bias and confounding in critical care health services research involving observational data. J Crit Care. 2006;21:1-7.

30. Tenner PA, Dibrell H, Taylor RP. Improved survival with hospitalists in a pediatric intensive care unit. Crit Care Med. 2003;31(3): $847-852$.

31. Gunning K, Rowan K. ABC of intensive care: outcome data and scoring systems. BMJ. 1999;319:241-244.

32. Eddleston JM, White P, Guthrie E. Survival, morbidity, and quality of life after discharge from intensive care. Crit Care Med. 2000;28(7): 2293-2299. 